\title{
Does the Motor Level of the Paretic Extremities Affect Balance in Poststroke Subjects?
}

\author{
Kamal Narayan Arya, Shanta Pandian, C. R. Abhilasha, and Ashutosh Verma
}

Pandit Deendayal Upadhyaya Institute for the Physically Handicapped (University of Delhi), Ministry of Social Justice and Empowerment, Government of India, 4 VD Marg, New Delhi 110002, India

Correspondence should be addressed to Kamal Narayan Arya; kamalnarya2@gmail.com

Received 14 February 2014; Revised 28 March 2014; Accepted 23 April 2014; Published 19 May 2014

Academic Editor: Keh-chung Lin

Copyright (C) 2014 Kamal Narayan Arya et al. This is an open access article distributed under the Creative Commons Attribution License, which permits unrestricted use, distribution, and reproduction in any medium, provided the original work is properly cited.

\begin{abstract}
Background. Poststroke impairment may lead to fall and unsafe functional performance. The underlying mechanism for the balance dysfunction is unclear. Objective. To analyze the relation between the motor level of the affected limbs and balance in poststroke subjects. Method. A prospective, cross-sectional, and nonexperimental design was conducted in a rehabilitation institute. A convenience sample of 44 patients was assessed for motor level using Brunnstrom recovery stage (BRS) and FuglMeyer Assessment: upper (FMA-UE) and lower extremities (FMA-LE). The balance was measured by Berg Balance Scale (BBS), Postural Assessment Scale for Stroke Patients (PASS), and Functional Reach Test (FRT). Results. BRS showed moderate correlation with BBS ( $\rho=0.54$ to $0.60 ; P<0.001)$, PASS $(r=0.48$ to $0.64 ; P<0.001)$ and FRT $(\rho=0.48$ to $0.59 ; P<0.001)$. FMA-UE also exhibited moderate correlation with BBS $(\rho=0.59 ; P<0.001)$ and PASS $(\rho=0.60 ; P<0.001)$. FMA-LE showed fair correlation with BBS $(\rho=0.50 ; P=0.001)$ and PASS $(\rho=0.50 ; P=0.001)$. Conclusion. Motor control of the affected limbs plays an important role in balance. There is a moderate relation between the motor level of the upper and lower extremities and balance. The findings of the present study may be applied in poststroke rehabilitation.
\end{abstract}

\section{Introduction}

Balance is an ability to maintain upright position within the base of support during static and dynamic positions [1]. Balance dysfunction, especially during maintenance of erect upright posture and walking, is a common poststroke consequence. Inability to maintain balance reduces functional performance and increases the fall frequency [2]. The dysfunction leads to various musculoskeletal complications multiplying the rehabilitation challenges [3-7].

In stroke, the exact mechanism underlying balance impairment is ambiguous [8]. The factors such as cognition, perception, and biomechanical alterations were found to be responsible for the impairment $[9,10]$.

A subject with hemiparesis bears more weight on the nonparetic lower extremity leading to asymmetry and impaired erect posture [11]. The weight-bearing asymmetry is associated with the increased postural sway and poor balance $[12,13]$. The inability of the nonaffected lower extremity to compensate for the paretic limb also contributes to the postural imbalance $[11,14]$. In addition, the arm movements have a considerable role in balance control. The movement of upper limbs usually appears prior to and during loss of balance. By reaching and grasping the outside support, the arms provide a protective function during the fall. The upper limb movements also prevent a fall by shifting the centre of gravity opposite to the direction of imbalance $[15,16]$. Due to the arm paresis, poststroke subjects exhibit poor protective function to maintain balance [17]. They demonstrate a deficit in anticipatory and reactive postural adjustments [10]. The impairment of affected lower and upper limbs does not permit the subject to recover from perturbations during functional tasks such as walking [11, 18-20].

In stroke, the voluntary limb movements may have a contribution in balance. However, no study has investigated the relation between the voluntary motor control of the limbs and balance impairment. The objective of the present study was to analyze the relation between the motor level 
of the affected upper and lower extremities and balance in poststroke subject.

\section{Methods}

2.1. Participants. Forty-four patients ( 34 men and 10 women) attending the Outpatient Occupational Therapy Department of Pandit Deendayal Upadhyaya Institute for the Physically Handicapped were selected for the study. The study protocol was approved by the ethics committee of the institute. The stroke subjects were briefed about the assessment procedure before they signed the informed consent. The subjects who met the following inclusion criteria were selected for the study: (1) chronic stroke (>6 months of onset), (2) ischemic or hemorrhagic stroke, (3) 35 to 65 years of age [21-23], and (4) Functional Ambulation Classification (FAC) [24] level 2 and above. The subjects were excluded from the study if they exhibited (1) cerebellar lesion, (2) multiple strokes, (3) severe cognitive and perceptual deficit, and (4) any acute medical illness.

This study was a prospective, cross-sectional, and nonexperimental design. The subjects were conveniently selected as per the inclusion criteria. A detailed clinical evaluation was performed and then the standardized assessments were applied. The assessments were carried out by two assessors who had 15 to 20 years of experience in stroke rehabilitation. One of the assessors applied the motor measures for all the subjects, while the other conducted the balance measures for them. Two sessions were allotted for the entire assessments, one for the motor level and the other for the balance assessment. All the assessment procedures were performed as per the standard guidelines of the respective scale.

2.2. Outcome Measures. Motor level was assessed by using Brunnstrom recovery stages (BRS) and Fugl-Meyer Assessment (FMA) for the upper and lower extremities [25, 26]. BRS is classified under six categories (1, flaccidity with no movement, to 6 , individual joint movement with little awkwardness) as per the motor recovery process of poststroke hemiparesis. The stages have been separately described for the upper extremity (BRS-UE), hand (BRS-H), and lower extremity (BRS-LE). BRS demonstrated strong responsiveness with the Motricity Index (effect size $d=0.97$, Wilcoxon $Z=5.33$, and $P<0.001 ; d=0.81, Z=5.09$, and $P<0.001)$ [27]. BRS was found to be highly valid $(r=$ $-0.81 ; P<0.001)$ when compared with neurophysiological measures [28]. However, there is no reporting of its reliability in the literature. FMA, a 3-point ordinal scale, measures the impairment of volitional movement ranging from 0 (items cannot be performed) to two (items can be fully performed). The upper extremity section of this scale (FMA-UE) is divided into two subsections: upper arm (FMA-UA) and wrist hand (FMA-WH). The section comprises nine items (6: upper arm; 3: wrist hand) with a sum score of 66 (36: upper arm; 30: hand). The lower extremity section (FMA-LE) has six items with a maximum score of 34 . In both the sections, items are further divided into different subcomponents. FMA demonstrated high reliability $(r=0.99)$ and good validity $(r=0.63$ to 0.88$)[29,30]$. It exhibited good responsiveness for the poststroke motor assessment [31].

The balance of the subjects was assessed by Berg Balance Scale (BBS), Postural Assessment Scale for Stroke Patients (PASS), and Functional Reach Test (FRT). BBS is used to assess static and dynamic balance abilities required for functional tasks. It comprises 14 items, scored on a 5-point ordinal scale ( 0 , poor balance, to 4 , good balance) with a maximum score of 56. The items range from unsupported sitting/standing to turn $360^{\circ}$ /standing upon one leg. The scale demonstrated excellent interrater as well as test-retest reliability (ICC $=0.91$ to 0.99 ) and internal consistency (Cronbach alpha $=0.92$ to 0.98 ), and its validity ranged from 0.55 to $0.91(r)[29,32,33]$. PASS assesses postural control on a 4-point ordinal scale ( 0 , cannot perform, to 3 , can perform independently) comprising 12 items (PASS-T), 5 for maintaining (PASS-M) and 7 for changing the posture (PASS-C). It showed excellent interrater agreement $(\mathrm{ICC}=0.97)$ and high internal consistency (Cronbach $=0.93$ ). Further, it showed acceptable validity, ranging from 0.73 to $0.89(r)$ [34]. FRT is a quick and performance-based test to assess dynamic postural control during a functional activity. It is measured as a maximal forward-reaching distance beyond the arm's length while maintaining the standing position. The normal range varies from 10.5 to 16.7 inches depending on the age and gender [33]. The reliability of FRT ranges from 0.92 to 0.98 (ICC), while the validity varies from 0.65 to $0.71(r)$. In the present study, the measurement was performed on the lessaffected upper extremity [29].

2.3. Data Analysis. Data analysis was performed using IBM SPSS, version 21.0. The Spearman test $(\rho)$ was used to find the relation between the measures of motor level and balance. Relation between the individual items of each motor outcome measure with that of the balance measures was analyzed using the same test. The level of relation corresponding to the correlation coefficient was followed as low ( $<0.5 ; P<0.05)$, moderate $(0.5$ to $0.69 ; P<0.05)$, and high $(0.7$ to $0.89 ; P<0.05)$ [35]. Furthermore, subgroup and partial correlation analysis were also conducted. The significance level was set at $P<0.05$.

\section{Results}

All the enrolled subjects completed the assessment protocol. The mean age of the participants was $48.82 \pm 12.04$ years. The average poststroke duration was $19.73 \pm 12.21$ months. Twenty-six (59\%) subjects had right side paresis. Three subjects $(7 \%)$ exhibited the hand dominance for left side. Table 1 shows the detailed demographic characteristics of the participants. Thirty-two $(72.5 \%)$ subjects were at stages III to IV of BRS-UE, while 31 (70\%) were at stages III to IV of BRS-LE. The mean BBS of the subjects was $42.64 \pm 10.35$. Table 2 shows the description of the motor level and balance as assessed by the outcome measures.

On analyzing the relation between the measures of motor level and balance, moderate correlation ( $\rho=0.5$ to 0.7$)$ was found between most of the variables. BRS-UE, BRS-H, and 


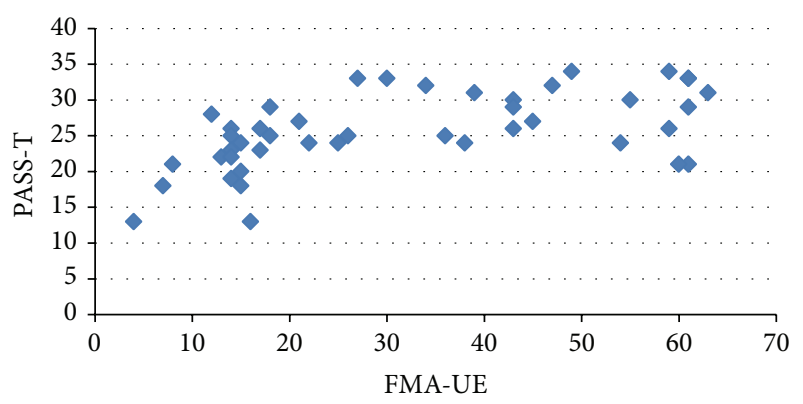

(a)

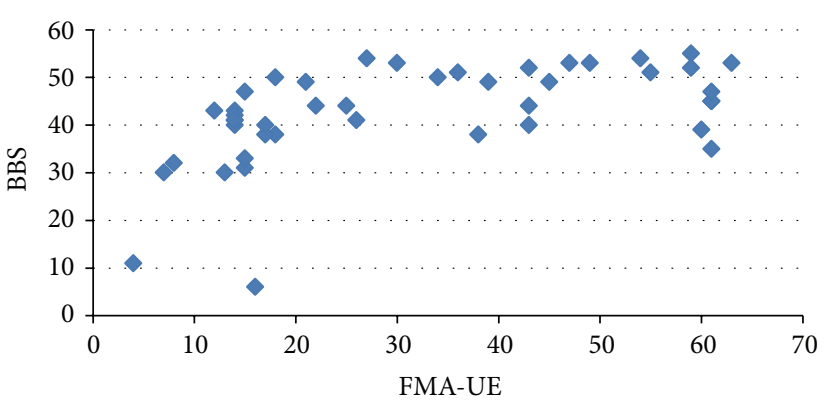

(b)

FIGURE 1: (a) Showing the relation between the total score of Fugl-Meyer Assessment: upper extremity (FMA-UE) and Postural Assessment Scale for Stroke (PASS-T). (b) Showing the relation between the total score of Fugl-Meyer Assessment: upper extremity (FMA-UE) and total score of Berg Balance Scale (BBS).

TABLE 1: Demographic characteristics of the participants.

\begin{tabular}{|c|c|}
\hline Characteristics & Number $(\%) /$ mean \pm SD \\
\hline \multicolumn{2}{|c|}{ Number of participants (44) } \\
\hline Male/female & $34(77 \%) / 10(23 \%)$ \\
\hline Age (in years) & $48.82 \pm 12.04$ \\
\hline Poststroke duration (in months) & $19.73 \pm 12.21$ \\
\hline Side of involvement (right/left) & $26(59 \%) / 18(41 \%)$ \\
\hline Handedness (right/left) & $41(93 \%) / 03(07 \%)$ \\
\hline \multicolumn{2}{|c|}{ Type of stroke } \\
\hline Ischemic/hemorrhagic & $28(64 \%) / 16(36 \%)$ \\
\hline \multicolumn{2}{|c|}{ Area of involvement } \\
\hline Frontoparietal & $12(27 \%)$ \\
\hline Basal ganglia & $04(09 \%)$ \\
\hline Thalamus & $06(14 \%)$ \\
\hline Internal capsule & $02(4.5 \%)$ \\
\hline Multiple & $20(45.5 \%)$ \\
\hline \multicolumn{2}{|c|}{ Risk factor } \\
\hline Hypertensive & $32(77 \%)$ \\
\hline Hereditary & $15(34 \%)$ \\
\hline Smoking & $12(27 \%)$ \\
\hline Alcoholic & $17(39 \%)$ \\
\hline Diabetic & $08(18 \%)$ \\
\hline Obesity & $07(16 \%)$ \\
\hline
\end{tabular}

SD: standard deviation.

BRS-LE showed moderate correlation with BBS ( $\rho=0.54$ to $0.60 ; P<0.001)$, PASS ( $\rho=0.48$ to $0.64 ; P \leq 0.001$ ), and FRT ( $\rho=0.48$ to $0.59 ; P \leq 0.001)$. FMA-UE, including FMA-UA, also exhibited moderate correlation with BBS $(\rho=0.59$ to $0.63 ; P<0.001)$ and PASS $(\rho=0.54$ to $0.62 ; P<0.001)$. Figures 1(a) and 1(b) show the relation between the FMA$\mathrm{UE}$ and BBS and PASS-T. FMA-UE along with FMA-WH demonstrated low relation with FRT. However, FMA-UA alone was found to be related to FRT $(\rho=0.50 ; P=0.002)$. Figure 2 showed the relation between FMA-UA and FRT. FMA-LE demonstrated fair correlation with $\operatorname{BBS}(\rho=0.50$; $P=0.001)$ and PASS $(\rho=0.50 ; P=0.001)$. It showed poor

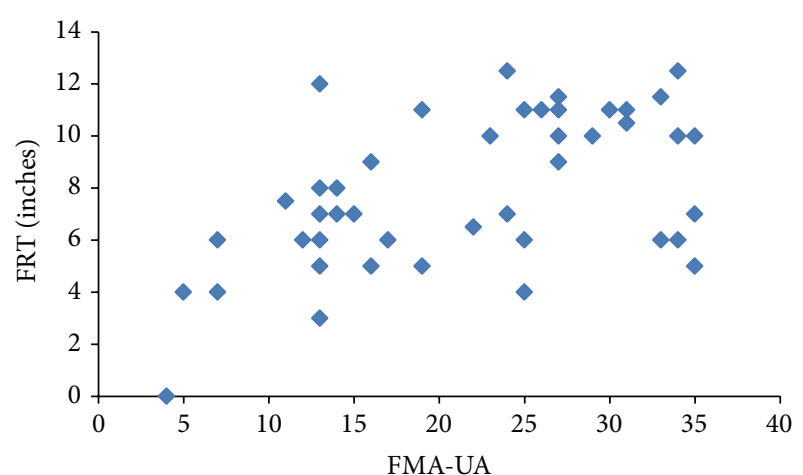

FIGURE 2: Showing the relation between the upper arm subscore of Fugl-Meyer Assessment (FMA-UA) and Functional Reach Test (FRT).

relation with PASS-C while showing no relation with FRT. Table 3 shows the detailed $\rho$ value for all the variables.

Further, on exploring the relation between the individual items of FMA with the same of BBS, FMA-UE items II (flexor synergy), III (extensor synergy), and IV (movement out of synergy) were found to have moderate correlation ( 0.50 to $0.64 ; P=0.001$ to 0.003 ) with most of the BBS items (except items 1, 2, 3, 5, and 6). FMA wrist-hand items (VII and VIII) also exhibited moderate relation with BBS items 4, 7, and 9 (0.50 to 0.58 and $P<0.001$ to 0.002 ). FMA IX showed moderate relation with BBS items 4 to 12 (ranging from 0.50 to $0.65 ; P<0.001$ to 0.002 ). FMA-UE items II, III, IV, and IX demonstrated significant correlation with total BBS (0.46 to 0.66; $P<0.001$ to 0.002 ). All items of FMA-UE (except I and II) showed good relation with PASS item 3 (standing with support) (0.50 to $0.58 ; P<0.001)$. FMA-UE items II to $\mathrm{V}$ were found to be significantly related $(0.45$ to $0.66 ; P<0.001$ to 0.003 ) with PASS-C items 6 to 10 . FMA-UE II to IV also exhibited moderate correlation with total PASS score ( 0.55 to 0.65; $P<0.001)$. FMA-UE VII, VIII, and IX demonstrated correlation with PASS item $6(0.45$ to 0.53 and $P<0.001$ to 0.002). FMA-UE VII and IX were found to be related to PASS item 10 (0.45 to 0.47 and $P<0.001$ to 0.002$)$. Same components of FMA-UE showed good relation with total 
TABLE 2: Description of motor recovery and balance measures.

\begin{tabular}{|c|c|c|c|c|c|c|}
\hline Outcome measures & Stage I & Stage II & Stage III & Stage IV & Stage V & Stage VI \\
\hline BRS-A & $00(0 \%)$ & $04(9 \%)$ & $20(45.5 \%)$ & $12(27 \%)$ & $07(16 \%)$ & $01(2 \%)$ \\
\hline BRS-H & $00(0 \%)$ & $20(45.5 \%)$ & $10(23 \%)$ & $07(16 \%)$ & $06(13.5 \%)$ & $01(2 \%)$ \\
\hline \multirow[t]{2}{*}{ BRS-LE } & $01(2 \%)$ & $02(4.5 \%)$ & $12(27 \%)$ & $19(43 \%)$ & $10(23 \%)$ & $00(0 \%)$ \\
\hline & \multicolumn{6}{|c|}{ Mean \pm SD } \\
\hline $\begin{array}{l}\text { FMA-UE } \\
\text { (maximum score-66) }\end{array}$ & \multicolumn{6}{|c|}{$31.98 \pm 18.92$} \\
\hline $\begin{array}{l}\text { FMA-UA } \\
\text { (maximum score-36) }\end{array}$ & \multicolumn{6}{|c|}{$21.59 \pm 9.23$} \\
\hline $\begin{array}{l}\text { FMA-WH } \\
(\text { maximum score-30) }\end{array}$ & \multicolumn{6}{|c|}{$10.39 \pm 9.51$} \\
\hline $\begin{array}{l}\text { FMA-LE } \\
\text { (maximum score-34) }\end{array}$ & \multicolumn{6}{|c|}{$19.64 \pm 5.10$} \\
\hline $\begin{array}{l}\text { BBS } \\
\text { (maximum score-56) }\end{array}$ & \multicolumn{6}{|c|}{$42.64 \pm 10.35$} \\
\hline $\begin{array}{l}\text { PASS-T } \\
(\text { maximum score-36) }\end{array}$ & \multicolumn{6}{|c|}{$25.75 \pm 5.30$} \\
\hline $\begin{array}{l}\text { PASS-M } \\
\text { (maximum score-15) }\end{array}$ & \multicolumn{6}{|c|}{$10.45 \pm 2.18$} \\
\hline $\begin{array}{l}\text { PASS-C } \\
\text { (maximum score-21) }\end{array}$ & \multicolumn{6}{|c|}{$15.30 \pm 3.46$} \\
\hline FRT (in inches) & \multicolumn{6}{|c|}{$7.87 \pm 2.94$} \\
\hline
\end{tabular}

BRS: Brunnstrom recovery stages, A: arm, H: hand, FMA: Fugl-Meyer Assessment, UE: upper extremity, UA: upper arm, WH: wrist and hand, BBS: Bergs Balance Scale, PASS: Postural Assessment Scale for Stroke Patients, T: total, M: maintenance of posture, C: change in posture, FRT: Functional Reach Test, and SD: standard deviation.

TABLE 3: Relation between the motor recovery and balance measures.

\begin{tabular}{|c|c|c|c|c|c|}
\hline & BBS & PASS-C & PASS-M & PASS-T & FRT \\
\hline BRS-A & $\begin{array}{c}\rho=0.60 \\
(P<0.001)\end{array}$ & $\begin{array}{c}\rho=0.64 \\
(P<0.001)\end{array}$ & $\begin{array}{c}\rho=0.55 \\
(P<0.001)\end{array}$ & $\begin{array}{c}\rho=0.63 \\
(P<0.001)\end{array}$ & $\begin{array}{c}\rho=0.59 \\
(P<0.001)\end{array}$ \\
\hline BRS-H & $\begin{array}{c}\rho=0.55 \\
(P<0.001)\end{array}$ & $\begin{array}{c}\rho=0.50 \\
(P=0.001)\end{array}$ & $\begin{array}{c}\rho=0.50 \\
(P=0.001)\end{array}$ & $\begin{array}{c}\rho=0.52 \\
(P<0.001)\end{array}$ & $\begin{array}{c}\rho=0.55 \\
(P<0.001)\end{array}$ \\
\hline BRS-LE & $\begin{array}{c}\rho=0.54 \\
(P<0.001)\end{array}$ & $\begin{array}{c}\rho=0.51 \\
(P<0.001)\end{array}$ & $\begin{array}{c}\rho=0.55 \\
(P<0.001)\end{array}$ & $\begin{array}{c}\rho=0.57 \\
(P<0.001)\end{array}$ & $\begin{array}{c}\rho=0.48 \\
(P=0.001)\end{array}$ \\
\hline FMA-UE & $\begin{array}{c}\rho=0.59 \\
(P<0.001)\end{array}$ & $\begin{array}{c}\rho=0.56 \\
(P<0.001)\end{array}$ & $\begin{array}{c}\rho=0.54 \\
(P<0.001)\end{array}$ & $\begin{array}{c}\rho=0.60 \\
(P<0.001)\end{array}$ & $\begin{array}{c}\rho=0.38 \\
(P=0.01)\end{array}$ \\
\hline FMA-UA & $\begin{array}{c}\rho=0.63 \\
(P<0.001)\end{array}$ & $\begin{array}{c}\rho=0.59 \\
(P<0.001)\end{array}$ & $\begin{array}{c}\rho=0.58 \\
(P<0.001)\end{array}$ & $\begin{array}{c}\rho=0.62 \\
(P<0.001)\end{array}$ & $\begin{array}{c}\rho=0.50 \\
(P=0.002)\end{array}$ \\
\hline FMA-WH & $\begin{array}{c}\rho=0.50 \\
P=0.001\end{array}$ & $\begin{array}{c}\rho=0.50 \\
P=0.001\end{array}$ & $\begin{array}{c}\rho=0.43 \\
P<0.003\end{array}$ & $\begin{array}{c}\rho=0.50 \\
(P<0.001)\end{array}$ & $\begin{array}{l}\rho=0.30 \\
P<0.04\end{array}$ \\
\hline FMA-LE & $\begin{array}{c}\rho=0.50 \\
(P=0.001)\end{array}$ & $\begin{array}{c}\rho=0.41 \\
(P=0.006)\end{array}$ & $\begin{array}{c}\rho=0.50 \\
(P=0.001)\end{array}$ & $\begin{array}{c}\rho=0.50 \\
(P=0.001)\end{array}$ & NS \\
\hline
\end{tabular}

BRS: Brunnstrom recovery stages, A: arm, H: hand, FMA: Fugl-Meyer Assessment, UA: upper arm, WH: wrist and hand, UE: upper extremity, PASS: Postural Assessment Scale for Stroke Patients, C: change in posture, M: maintenance of posture, FRT: Functional Reach Test, BBS: Berg Balance Scale, $\rho$ : Spearman test, and NS: not significant.

PASS (0.50 to $0.51 ; P<0.001)$. FMA-UE items II, III, and IV displayed low relation with FRT $(0.45$ to $0.48 ; P<0.001$ to 0.002 ). All other FMA-UE items did not demonstrate any relation with FRT.

BBS and FMA-LE item II (flexor synergy) were found to be related to BBS items $5,8,11,12$, and 14 and overall total BBS ( $\rho=0.50$ to 0.60 and $P<0.001$ for all). FMA-LE item IV showed significant correlation with two items of BBS (8 and 14) and total BBS ( $\rho=0.45$ to 0.47 and $P=0.001$ to 0.002). Only 2 FMA-LE items (III and IV) were found to be related to PASS items $3,4,8,9$, and 10 ( $\rho=0.47$ to 0.58 and $P \leq 0.001)$. The items also related to PASS-M ( $\rho=0.49$ to $0.53 ; P \leq 0.001)$ and total PASS score ( $\rho=0.48$ to 0.52 and $P \leq 0.001)$. Figures $3(\mathrm{a})$ and $3(\mathrm{~b})$ show the relation between the FMA-LE and BBS and PASS-T. None of the items of FMALE was found to be related to FRT. 


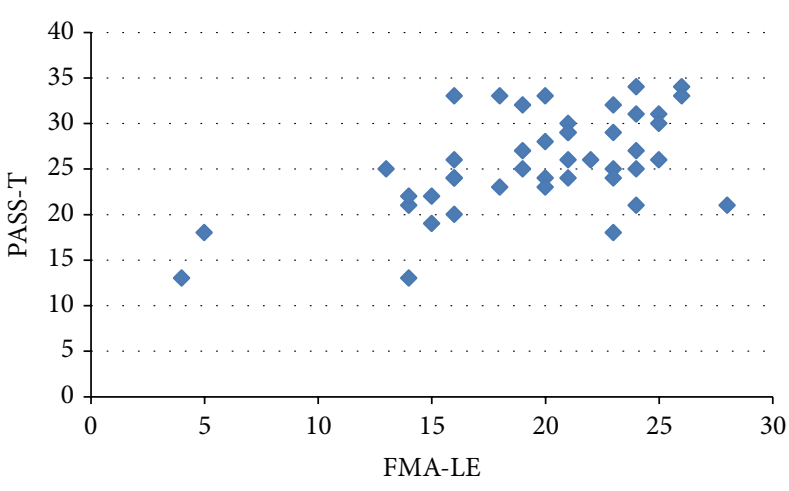

(a)

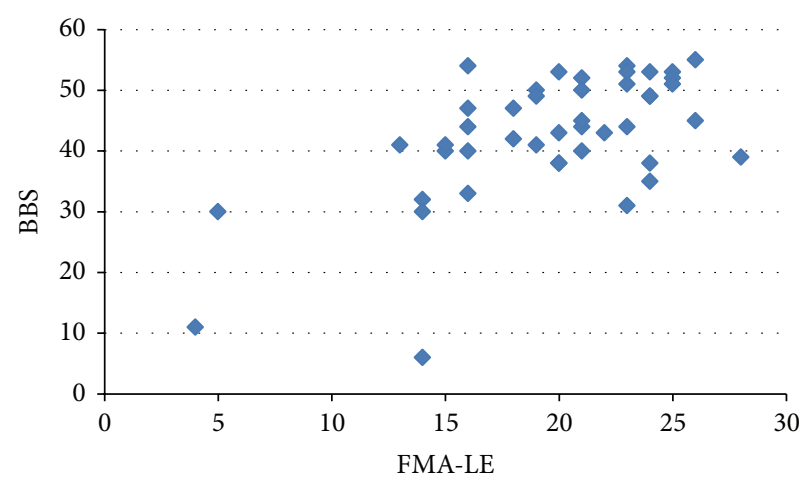

(b)

FIGURE 3: (a) Showing the relation between the total score of Fugl-Meyer Assessment: lower extremity (FMA-LE) and Postural Assessment Scale for Stroke (PASS-T). (b) Showing the relation between the total score of Fugl-Meyer Assessment: lower extremity (FMA-LE) and total scores of Berg Balance Scale (BBS).

The scores of balance measures were not found to be significantly different between the subgroups based on the side of involvement (dominant/nondominant side) and gender. Only FRT of male subjects $(8.44 \pm 2.98$ inches) was found to be higher than the female subjects $(5.95 \pm 1.80$ inches $)$ with $P<0.008$.

Partial correlation analysis was also performed to neutralize the effect of FMA-UE and FMA-LE on one another, when inferring the relation with balance measures. By controlling FMA-LE, no relation was found between FMA-UE and BBS, while, on controlling FMA-UE, FMA-LE demonstrated low significant relation with BBS $(\rho=0.38 ; P<0.012)$. Both FMA-UE and FMA-LE exhibited no relation with PASS-T when one of the FMA (FMA-LE / FMA-UE) components was controlled.

\section{Discussion}

Balance is a complex motor behavior and involves multiple sensorimotor, environmental, and functional contexts, required during functional performance [9]. In other words, all factors, such as biomechanical constraint, cognition, perception, somatosensation, and motor control, affect the balance ability. Apart from the paretic lower limb, the upper extremity may also be responsible for poor balance $[13,15]$.

To date, no study has inferred the relation between the motor level of the limbs and balance in stroke. Most of the studies have been done focusing either on the weightbearing and functional issues or on the validity aspect of a measure [11, 12, 14, 36, 37]. This study utilized multiple measures for assessing motor level and balance. The three balance measures were used to examine the various simple to complex balance-related tasks. In addition, the relation was investigated between individual movement and balance components. The findings of the present study revealed a positive relation between the motor level of the paretic limbs and balance in stroke subjects.
After stroke, the paretic upper limb is unable to execute voluntary movements, usually needed before and during losing the balance. The findings of the present study indicated that the lower the motor level of the upper limb the poorer the balance. Although the role of arm movement in balance control is evident to the healthy individuals, no study confirms the same in stroke subjects $[15,16]$.

Due to hemiparesis of the body, the centre of gravity shifts to the stronger side of the body. Weight-bearing asymmetry is the most common reason proposed for balance deficit among stroke survivors $[11,12]$. The lower extremity recovery level exhibited moderate relation with BBS and PASS-T. However, FMA-LE assesses only voluntary movements of the lower limb and does not have any weight-bearing item. It may be inferred that the ability to carry out voluntary leg movements is necessary for maintaining balance, for example, the stepping strategy, the ability to take forward or sideward step to prevent falling [33].

Fall is the most common complication in poststroke subjects, and the fear of fall or anticipatory behaviour leads to reduced physical activity [38]. The average BBS of the study participants was 42.6 . The scores below 45 were considered as increased risk for falls [39]. However, the relation of BBS scores between fallers and nonfallers is still controversial [20]. In the present study, 18 (41\%) subjects reported fear of fall, $14(32 \%)$ had history of occasional fall, and 12 (27\%) had the frequent fall prior to the rehabilitation management. All the participants were undergoing conventional rehabilitation for more than 3 months. None of the subjects reported fall after the commencement of the management.

FRT was not found to be related to both FMA-UE and FMA-LE. This could be due to the assessment of FRT using the less-affected upper limb. In comparison to other balance measures, FRT assesses only reaching ability. BBS, apart from reaching, comprises multiple balance-related tasks in static and dynamic positions. PASS exclusively measures strokerelated postural impairment. Although some of the items overlap with that of the BBS, PASS specifically assesses paretic side and bed mobility. 
Simultaneous recovery of the affected upper and lower limbs may influence the balance control. In the present study, the effect of motor level of one limb (upper or lower) was controlled while analyzing the relation of recovery with balance. It could be inferred that the balance is not related to either upper or lower limb independently. Rather, balance is an integrated response of the performance of the upper extremities while maintaining upright position by the lower extremities.

A good correlation was found between the recovery of affected limb (upper limb and lower limb independently) and balance. However, the level of relation declined when both the affected limbs were considered as a single unit. Both FMA-UE and FMA-LE exhibited no relation with PASS-T when one of the FMA (FMA-LE/FMA-UE) components was controlled.

FMA-UE components exhibited good relation with the majority of BBS items. The items were either those which required control through protective extension such as standto-sit or complex items ( 9 and beyond) comprising the upper limb control and manipulation. Similarly, FMA-UA components exhibited good relation with most of the PASS$\mathrm{C}$ items, which required the upper extremity control during postural change. Both synergistic and nonsynergistic FMALE components demonstrated acceptable association with BBS items such as reaching forward while standing and standing upon one leg.

Different approaches such as task-oriented gait training are used to alleviate balance dysfunction in stroke [40]. Despite evidence, no single approach is considered to be the best to achieve balance in stroke subjects [41]. The arm training improves postural control and independent walking [42, 43]. Exclusive task-oriented arm training in standing may improve postural control (centre of pressure displacement and the anticipatory adjustments) [42, 44]. The role of the limbs in balance control may be utilized in stroke rehabilitation. The present study had few limitations, for instance, variability in age, chronicity, and lesioned area. The number of female participants was considerably low. The trunk impairment may also affect balance. However, the trunk control was not assessed in the study. Further, due to nonavailability of the reliability, only the validity as a psychometric value was considered for BRS.

Advance measures such as kinematic analysis and force place may be used for future studies. Interaction of rehabilitation intervention on recovery and balance may be investigated in the longitudinal studies.

\section{Conclusion}

Balance, a multifactorial phenomenon, required for safe functional performance, gets impaired in stroke. In the present study, there exists a positive relation between the motor level of the affected upper and lower extremities and balance among poststroke subjects. Voluntary motor control of the paretic limbs may be one of the factors in balancerelated functions. The findings may be utilized in planning stroke rehabilitation program.

\section{Conflict of Interests}

The authors declare that there is no conflict of interests regarding the publication of this paper.

\section{Acknowledgment}

The present study was partially funded by the Pandit Deendayal Upadhyaya Institute for the Physically Handicapped, 4 Vishnu Digamber Marg, New Delhi, India.

\section{References}

[1] S. F. Tyson, M. Hanley, J. Chillala, A. Selley, and R. C. Tallis, "Balance disability after stroke," Physical Therapy, vol. 86, no. 1, pp. 30-38, 2006

[2] A. A. Schmid, M. van Puymbroeck, P. A. Altenburger et al., "Balance and balance self-efficacy are associated with activity and participation after stroke: a cross-sectional study in people with chronic stroke," Archives of Physical Medicine and Rehabilitation, vol. 93, no. 6, pp. 1101-1107, 2012.

[3] J. E. Harris, J. J. Eng, D. S. Marigold, C. D. Tokuno, and C. L. Louis, "Relationship of balance and mobility to fall incidence in people with chronic stroke," Physical Therapy, vol. 85, no. 2, pp. 150-158, 2005.

[4] V. Weerdesteyn, M. de Niet, H. J. R. van Duijnhoven, and A. C. H. Geurts, "Falls in individuals with stroke," Journal of Rehabilitation Research and Development, vol. 45, no. 8, pp. 1195-1214, 2008.

[5] M. Rensink, M. Schuurmans, E. Lindeman, and T. B. Hafsteinsdóttir, "Falls: incidence and risk factors after stroke-a systematic literature review," Tijdschrift voor Gerontologie en Geriatrie, vol. 40, no. 4, pp. 156-167, 2009.

[6] P. Lisiński, J. Huber, E. Gajewska, and P. Szłapiński, “The body balance training effect on improvement of motor functions in paretic extremities in patients after stroke-a randomized, single blinded trial," Clinical Neurology and Neurosurgery, vol. 114, no. 1, pp. 31-36, 2012.

[7] J. Y. Lim, S. H. Jung, W. S. Kim, and N. J. Paik, "Incidence and risk factors of poststroke falls after discharge from inpatient rehabilitation,” $P M$ \& $R$, vol. 4, no. 12, pp. 945-953, 2012.

[8] M. Mihara, I. Miyai, N. Hattori et al., "Cortical control of postural balance in patients with hemiplegic stroke," Neuroreport, vol. 23, no. 5, pp. 314-319, 2012.

[9] C. B. de Oliveira, I. R. T. de Medeiros, N. A. F. Frota, M. E. Greters, and A. B. Conforto, "Balance control in hemiparetic stroke patients: main tools for evaluation," Journal of Rehabilitation Research and Development, vol. 45, no. 8, pp. 1215-1226, 2008.

[10] J. Carr and R. Shepherd, Stroke Rehabilitation: Guidelines for Exercises and Training to Optimize Motor Skill, ButterworthHeinemann, London, UK, 1st edition, 2003.

[11] A. Mansfield, G. Mochizuki, E. L. Inness, and W. E. McIlroy, "Clinical correlates of between-limb synchronization of standing balance control and falls during inpatient stroke rehabilitation," Neurorehabilitation and Neural Repair, vol. 26, no. 6, pp. 627-635, 2012.

[12] J. F. Kamphuis, D. de Kam, A. C. Geurts, and V. Weerdesteyn, "Is weight-bearing asymmetry associated with postural instability after stroke? A systematic review," Stroke Research and Treatment, vol. 2013, Article ID 692137, 13 pages, 2013. 
[13] J. Hendrickson, K. K. Patterson, E. L. Inness, W. E. McIlroy, and A. Mansfield, "Relationship between asymmetry of quiet standing balance control and walking post-stroke," Gait \& Posture, vol. 39, no. 1, pp. 177-181, 2014.

[14] N. Genthon, P. Rougier, A.-S. Gissot, J. Féroger, J. Pélissier, and D. Pérennou, "Contribution of each lower limb to upright standing in stroke patients," Stroke, vol. 39, no. 6, pp. 1793-1799, 2008.

[15] M. Shafeie, S. Manifar, M. Milosevic, and K. M. McConville, "Arm movement effect on balance," in Proceedings of the Annual International Conference of the IEEE Engineering in Medicine and Biology Society (EMBC '12), pp. 4549-4552, San Diego, Calif, USA, August-September 2012.

[16] M. Milosevic, K. M. V. McConville, and K. Masani, "Arm movement improves performance in clinical balance and mobility tests," Gait \& Posture, vol. 33, no. 3, pp. 507-509, 2011.

[17] M. Acar and G. K. Karatas, "The effect of arm sling on balance in patients with hemiplegia," Gait \& Posture, vol. 32, no. 4, pp. 641-644, 2010.

[18] T. Krasovsky, A. Lamontagne, A. G. Feldman, and M. F. Levin, "Reduced gait stability in high-functioning poststroke individuals," Journal of Neurophysiology, vol. 109, no. 1, pp. 7788, 2013.

[19] M. D. Lewek, C. E. Bradley, C. J. Wutzke, and S. M. Zinder, "The relationship between spatiotemporal gait asymmetry and balance in individuals with chronic stroke," Journal of Applied Biomechanics, vol. 30, no. 1, pp. 31-36, 2013.

[20] T. Baetens, A. de Kegel, P. Calders, G. Vanderstraeten, and D. Cambier, "Prediction of falling among stroke patients in rehabilitation," Journal of Rehabilitation Medicine, vol. 43, no. 10, pp. 876-883, 2011.

[21] G. F. Fuller, "Falls in the elderly," The American Family Physician, vol. 61, no. 7, pp. 2159-2168, 2173-2174, 2000.

[22] D. Griffiths and J. Sturm, "Epidemiology and etiology of young stroke," Stroke Research and Treatment, vol. 2011, Article ID 209370, 9 pages, 2011.

[23] B. Ovbiagele and M. N. Nguyen-Huynh, "Stroke epidemiology: advancing our understanding of disease mechanism and therapy," Neurotherapeutics, vol. 8, no. 3, pp. 319-329, 2011.

[24] J. Perry, M. Garrett, J. K. Gronley, and S. J. Mulroy, "Classification of walking handicap in the stroke population," Stroke, vol. 26, no. 6, pp. 982-989, 1995.

[25] A. R. Fugl-Meyer, L. Jaasko, I. Leyman, S. Olsson, and S. Steglind, "The post stroke hemiplegic patient. I. A method for evaluation of physical performance," Scandinavian Journal of Rehabilitation Medicine, vol. 7, no. 1, pp. 13-31, 1975.

[26] K. Sawner and J. LaVigne, Brunnstrom's Movement Therapy in Hemiplegia: A Neurophysiological Approach, JB Lippincott, Philadelphia, Pa, USA, 2nd edition, 1992.

[27] I. Safaz, B. Yilmaz, E. Yaşar, and R. Alaca, "Brunnstrom recovery stage and motricity index for the evaluation of upper extremity in stroke: analysis for correlation and responsiveness," International Journal of Rehabilitation Research, vol. 32, no. 3, pp. 228-231, 2009.

[28] S. Naghdi, N. N. Ansari, K. Mansouri, and S. Hasson, "A neurophysiological and clinical study of Brunnstrom recovery stages in the upper limb following stroke," Brain Injury, vol. 24, no. 11, pp. 1372-1378, 2010.

[29] E. Finch, D. Brooks, P. W. Stratford, and E. N. Mayo, Physical Rehabilitation Outcome Measures: A Guide to Enhanced Clinical Decision Making, Canadian Physiotherapy Association, Ontario, Canada, 2nd edition, 2002.
[30] J.-H. Lin, M.-J. Hsu, C.-F. Sheu et al., "Psychometric comparisons of 4 measures for assessing upper-extremity function in people with stroke," Physical Therapy, vol. 89, no. 8, pp. 840850, 2009.

[31] Y.-W. Hsieh, C.-Y. Wu, K.-C. Lin, Y.-F. Chang, C.-L. Chen, and J.-S. Liu, "Responsiveness and validity of three outcome measures of motor function after stroke rehabilitation," Stroke, vol. 40, no. 4, pp. 1386-1391, 2009.

[32] L. Blum and N. Korner-Bitensky, "Usefulness of the berg balance scale in stroke rehabilitation: a systematic review," Physical Therapy, vol. 88, no. 5, pp. 559-566, 2008.

[33] S. O'Sullivan and T. J. Schmitz, Eds., Physical Rehabilitation, F.A. Davis, Philadelphia, Pa, USA, 5th edition, 2007.

[34] C.-H. Wang, I.-P. Hsueh, C.-F. Sheu, and C.-L. Hsieh, "Discriminative, predictive, and evaluative properties of a trunk control measure in patients with stroke," Physical Therapy, vol. 85, no. 9, pp. 887-894, 2005.

[35] R. Carter, J. Lubinsky, and E. Domholdt, Eds., Rehabilitation Research: Principles and Applications, Elsevier Saunders, St. Louis, Mo, USA, 4th edition, 2011.

[36] M. Likhi, V. V. Jidesh, R. Kanagaraj, and J. K. George, "Does trunk, arm, or leg control correlate best with overall function in stroke subjects?" Topics in Stroke Rehabilitation, vol. 20, no. 1, pp. 62-67, 2013.

[37] S. Knorr, B. Brouwer, and S. J. Garland, "Validity of the community balance and mobility scale in community-dwelling persons after stroke," Archives of Physical Medicine and Rehabilitation, vol. 91, no. 6, pp. 890-896, 2010.

[38] K. Cho and G. Lee, "Impaired dynamic balance is associated with falling in post-stroke patients," The Tohoku Journal of Experimental Medicine, vol. 230, no. 4, pp. 233-239, 2013.

[39] B. L. D. Thorbahn and R. A. Newton, "Use of the berg balance test to predict falls in elderly persons," Physical Therapy, vol. 76, no. 6, pp. 576-583, 584-585, 1996.

[40] N. M. Salbach, N. E. Mayo, S. Robichaud-Ekstrand, J. A. Hanley, C. L. Richards, and S. Wood-Dauphinee, "The effect of a task-oriented walking intervention on improving balance selfefficacy poststroke: a randomized, controlled trial," Journal of the American Geriatrics Society, vol. 53, no. 4, pp. 576-582, 2005.

[41] A. C. H. Geurts, M. de Haart, I. J. W. van Nes, and J. Duysens, "A review of standing balance recovery from stroke," Gait \& Posture, vol. 22, no. 3, pp. 267-281, 2005.

[42] M. S. Waller and M. G. Prettyman, "Arm training in standing also improves postural control in participants with chronic stroke," Gait \& Posture, vol. 36, no. 3, pp. 419-424, 2012.

[43] S. S. Y. Au-Yeung, J. T. W. Ng, and S. K. Lo, "Does balance or motor impairment of limbs discriminate the ambulatory status of stroke survivors?" The American Journal of Physical Medicine and Rehabilitation, vol. 82, no. 4, pp. 279-283, 2003.

[44] A. Kubicki, G. Petrement, F. Bonnetblanc, Y. Ballay, and F. Mourey, "Practice-related improvements in postural control during rapid arm movement in older adults: a preliminary study," Journals of Gerontology A: Biological Sciences and Medical Sciences, vol. 67, no. 2, pp. 196-203, 2012. 


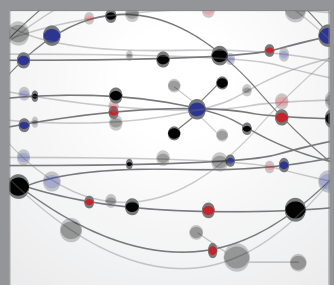

The Scientific World Journal
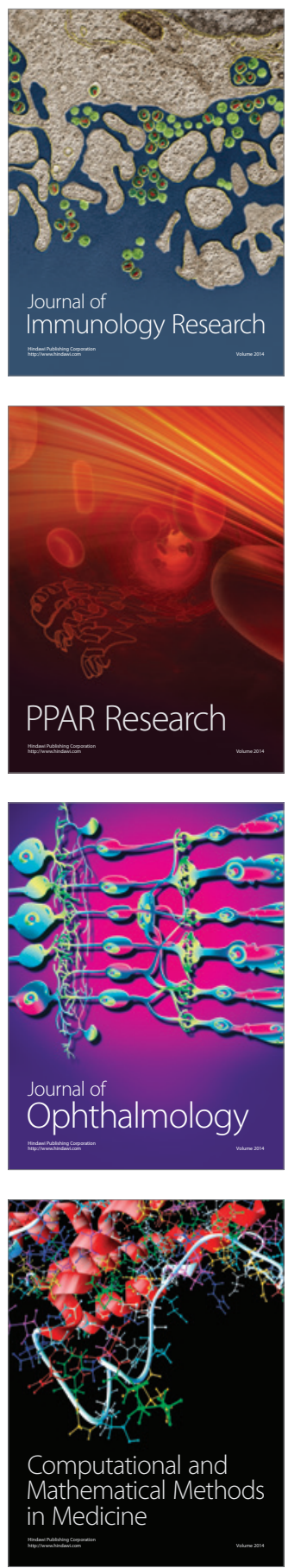

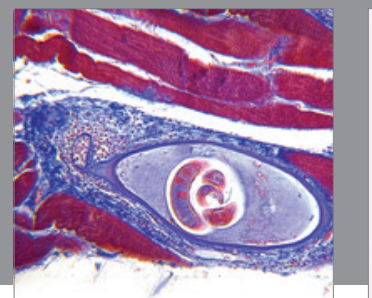

Gastroenterology

Research and Practice
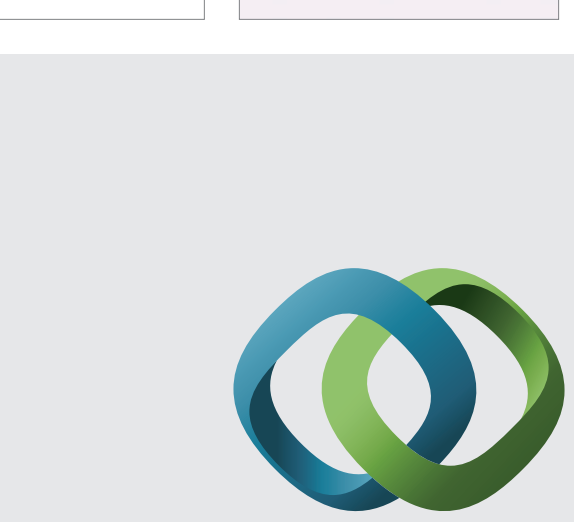

\section{Hindawi}

Submit your manuscripts at

http://www.hindawi.com
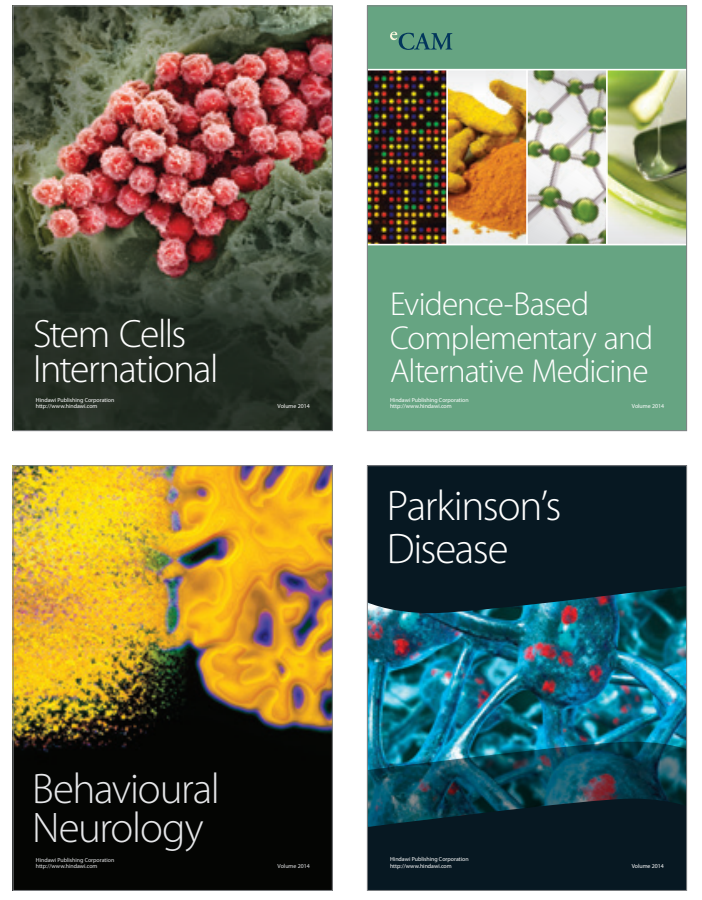
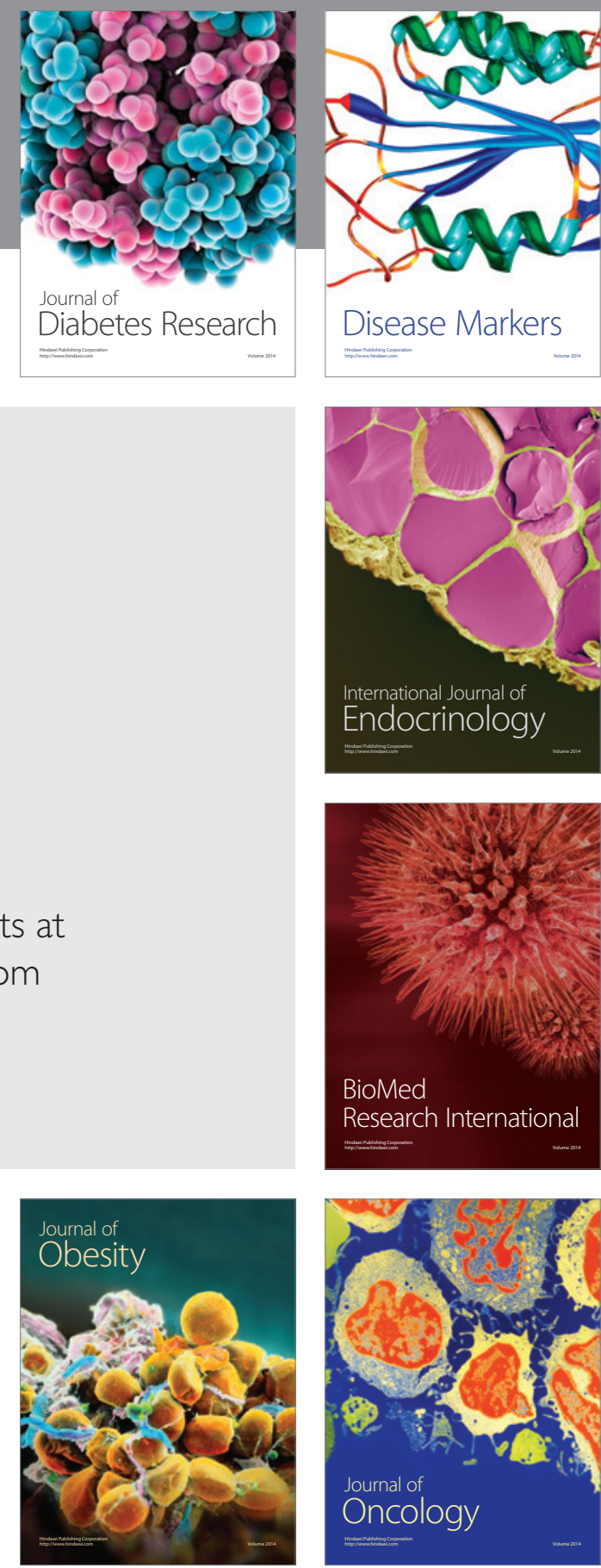

Disease Markers
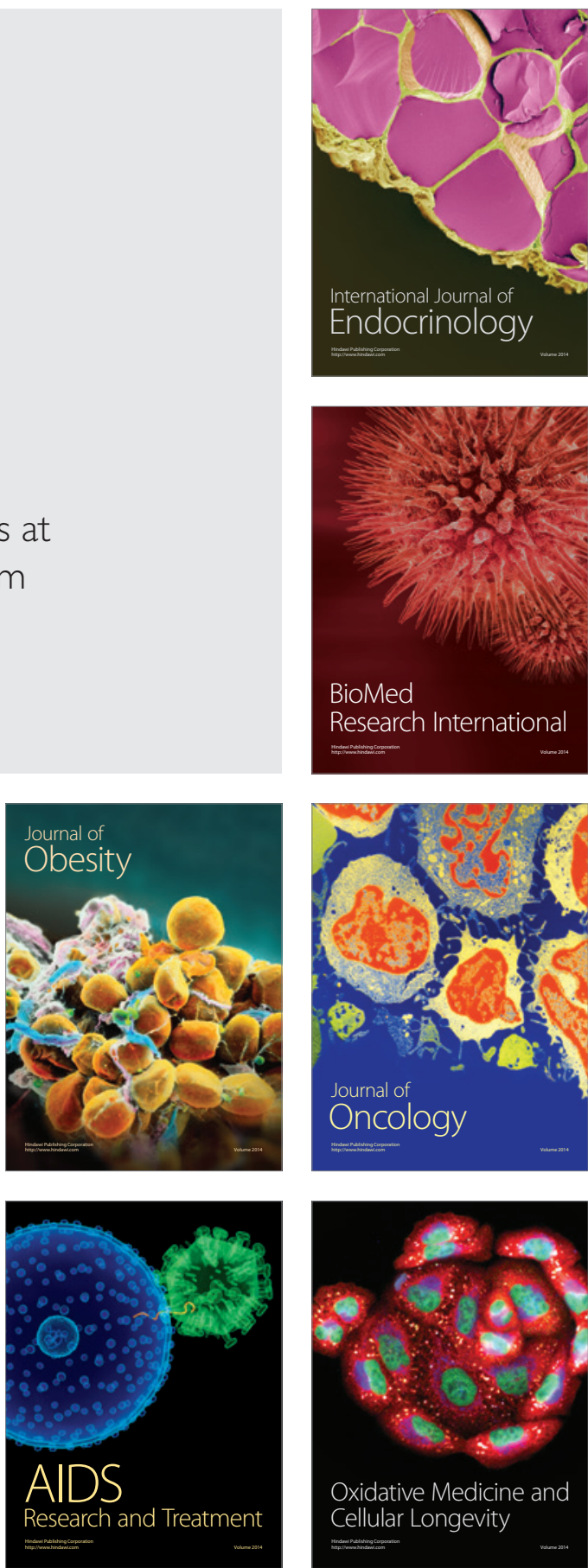